\title{
BMJ Global Health WHO and national lists of essential medicines in Mexico, Central and South America, and the Caribbean: are they adequate to promote paediatric endocrinology and diabetes care?
}

\author{
Amanda Rowlands, ${ }^{1,2}$ Alejandra Acosta-Gualandri, ${ }^{1}$ Jaime Guevara-Aguirre, ${ }^{3}$ \\ Jean-Pierre Chanoine ${ }^{1,2}$
}

To cite: Rowlands A, AcostaGualandri A, GuevaraAguirre J, et al. WHO and national lists of essential medicines in Mexico, Central and South America, and the Caribbean: are they adequate to promote paediatric endocrinology and diabetes care?. BMJ Global Health 2016;1:e000114 doi:10.1136/bmjgh-2016000114

- Additional material is available. To view please visit the journal (http://dx.doi.org/ 10.1136/bmjgh-2016000114).

Received 22 June 2016 Revised 30 September 2016 Accepted 3 October 2016

CrossMark

For numbered affiliations see end of article.

\section{Correspondence to} Dr Jean-Pierre Chanoine; jchanoine@cw.bc.ca

\section{ABSTRACT}

Paediatric endocrinology and diabetes is a paediatric specialty with less common conditions and higher cost medicines. Access to medicines for our specialty in low and middle income countries remains limited. We analysed the content of the WHO (children and adults) and of all available national Model Lists of Essential Medicines (EMLs) for Mexico, the Caribbean, Central and South America from a paediatric endocrinology and diabetes standpoint. A master list of medicines deemed necessary in paediatric endocrinology and diabetes was established and compared with the WHO and national EMLs, taking into account the gross national income. The WHO EMLs, which are largely recognised as an international benchmark and drive the content of the national EMLs, included many but not all medicines present on our master list. Interestingly, several national EMLs from richer countries included medicines that were not present in the WHO EMLs. Our analysis suggests that these medicines could be considered by the WHO for inclusion in their EMLs, which may promote the adoption of more medicines by individual countries. We also propose several changes to the WHO and national EMLs that could facilitate access to medicines in our specialty: age cut-off for a child using physical maturity rather than a set age limit; greater standardisation of the formatting of the national EMLs for easier comparison and collaborations between countries; greater emphasis on age-specificity and population-specificity for some medicines; and formatting of the EMLs in a diseasefocused manner rather than as individual medicines.

\section{INTRODUCTION}

In 2015, the United Nations (UN) developed an agenda that built on the achievements of the 2000 Millennium Declaration. ${ }^{1}$ Seventeen ambitious Sustainable Development Goals (SDGs) that cover most aspects of sustainable living were proposed. Importantly, while the Millennium Declaration did not focus specifically on

\section{Key questions}

What is already known about this topic?

- Capacity building in paediatric endocrinology and diabetes is increasing in South and Central America, the Caribbean and Mexico.

- Recognition of endocrine conditions and diabetes is improving, but access to affordable medicines that have long been used in high income countries remains poor.

- An extensive literature search through PubMed and through the WHO website did not yield any results about access to medicines for the treatment of paediatric endocrine conditions and diabetes in these countries.

\section{What are the new findings?}

- We developed a master list of medicines that are deemed most relevant by paediatric endocrinologists for the management of paediatric endocrine conditions and of diabetes.

- We identified which of these medicines are mentioned in the WHO Model Lists of Essential Medicines (EMLS).

- We compared the WHO EMLs and the national EMLs that are available for countries in South and Central America, the Caribbean and Mexico. We found marked differences between the content of the WHO and national EMLs. EMLS from richer countries usually included more medicines than those from poorer countries.

non-communicable diseases (NCDs), these are now an SDG target (SDG 3, 'to ensure healthy lives and promote well-being for all at all ages' $).{ }^{1}$ Inclusion of NCDs (which include paediatric endocrine conditions and diabetes) in the SDGs acknowledges their importance in the overall strategy for better health.

Global Pediatric Endocrinology and Diabetes (GPED) is a non-profit organisation endorsed by all major regional Pediatric 


\section{Key questions}

\section{Recommendations for policy}

- Medicines for non-communicable diseases such as paediatric endocrine conditions and diabetes need to become routinely available in low and middle income countries (LMICs).

- As a step towards this goal, the WHO EMLs and the national EMLs in LMICs should increase the number of medicines to improve management of less common conditions.

- In order to achieve the best care in the most rational manner, restrictions based, for example, on age and specificity of the diagnosis may need to be proposed.

Endocrine Societies and by the International Society for Pediatric and Adolescent Diabetes. GPED aims at improving the care of children with paediatric endocrine diseases and with diabetes who live in low and middle income countries (LMICs). ${ }^{2}$ When left untreated, these conditions are associated with high mortality or severe morbidity. A main objective of GPED is to help overcome the barriers preventing access to essential medicines in LMICs.

The past 10 years have seen a major increase in capacity in paediatric endocrinology and diabetes in LMICs. Training programmes that take place directly in the region where capacity is needed have been developed. In South America, the 'Sociedad Latina Americana de Endocrinología Pediátrica' (SLEP) organises an annual 'Summer School' that aims at 'promoting the development of future leaders in Paediatric Endocrinology'." Similarly, the Pediatric Endocrine Society, ${ }^{4}$ through its International Scholars Program, supports short stays in a North American institution for paediatric endocrinologists from various countries, including South and Central America. As a consequence of increased capacity, more children and adolescents are now diagnosed in a timely fashion.

Unfortunately, access to medicines that have been used for decades in high income countries (HICs), which are affordable and are most often out of patent, remains low in many LMICs and prevents appropriate lifelong management of paediatric endocrine conditions. ${ }^{5}$ In the field of paediatric endocrinology and diabetes, several organisations are facing this reality on a day-to-day basis. Caring and Living as Neighbours $(\mathrm{CLAN})^{6}$ is supporting patients and families in their quest to access fludrocortisone and hydrocortisone (for the management of congenital adrenal hyperplasia) and bisphosphonates (for the management of osteogenesis imperfecta) mainly in Asia. The International Diabetes Federation 'Life for a Child' Programme ${ }^{7}$ supports global diabetes management at the request of local established diabetes centres and supports 46 countries including Mexico, Central America (Guatemala), the Caribbean (Cayman Islands, Dominican Republic, Haiti, Jamaica, Santa Lucia) and South America (Bolivia,
Ecuador, Guyana). The CARE Foundation ${ }^{8}$ regularly receives requests from desperate families with children presenting with congenital adrenal hyperplasia who live in LMICs.

\section{WHAT MEDICINES ARE NEEDED FOR THE MANAGEMENT OF PAEDIATRIC ENDOCRINE DISEASES AND DIABETES?}

There are no Clinical Practice Guidelines that provide a master list of medicines used in our specialty. Therefore, a master list of most commonly used medicines was developed. The list was prepared by J-PC and discussed during a focus group by the paediatric endocrinologists at British Columbia Children's Hospital and by two paediatric endocrinologists in Central and South America (AA and JG-A). Each medicine was added to the master list based on consensus. Table 1 (left column) provides a list of medicines or groups of medicines that are deemed necessary for the management of the main paediatric endocrine conditions and of diabetes. Only the non-proprietary names of the medicines were considered. Chemically distinct medicines that have similar effects and are used interchangeably around the world were listed as one category and discussed as one medicine (for instance methimazole and carbimazole are used interchangeably as antithyroid medications). Chemically distinct medicines from the same family but with different potency (for instance, alendronate and pamidronate belong to the bisphosphonates family and have different potency and availability in different countries) were listed in the same category but discussed separately. Although paediatric endocrinologists might prefer to use one medicine over the other because of specific pharmacological characteristics, it was felt that hydrocortisone, prednisone or prednisolone can all be used for the replacement of cortisol. Similarly, most patients with diabetes can be treated with the human or the analogue form of a short-acting and a long-acting insulin. ${ }^{9}$ Some of the medicines are life-saving, such as insulin or corticosteroids. Others prevent severe morbidity, such as L-thyroxine or bisphosphonates. The cost of the medicines differs from setting to setting and can vary from a few cents a day (eg, thyroid hormones) to several dollars a day (eg, insulin).

Medicines used in paediatric endocrinology and diabetes do not all meet the criteria of 'essential medicines' as defined by an expert panel of the WHO which states that 'An essential drug is a drug needed to satisfy the health needs of the majority of the population and it should be available at all times in adequate amounts and in the appropriate dosage forms' ${ }^{10}$ However, while most conditions seen in paediatric endocrinology are not relevant to the majority of a population, they affect thousands of children around the world. Similar to CLAN, we feel that in 2016, children with chronic health conditions should be entitled to affordable access to appropriate medicines. ${ }^{6}$ 
Table 1 Medicines commonly used in paediatric endocrinology and diabetes included in the WHO EML for children, for adults and in the national EMLs

\begin{tabular}{|c|c|c|c|}
\hline \multirow[b]{2}{*}{ List of medicines for paediatric endocrinology and diabetes } & \multicolumn{2}{|l|}{ WHO } & \multirow[b]{2}{*}{ National lists $(\%)^{\star}$} \\
\hline & Child & Adult & \\
\hline \multicolumn{4}{|l|}{ Adrenal } \\
\hline Dexamethasone (PO) & $\mathrm{x}$ & $\mathrm{x}$ & 76 \\
\hline Fludrocortisone (PO) & $\mathrm{x}$ & $\mathrm{x}$ & 48 \\
\hline \multicolumn{4}{|l|}{ Thyroid } \\
\hline L-thyroxine (PO) & $\mathrm{x}$ & $\mathrm{x}$ & 100 \\
\hline PTU or methimazole or carbimazole (PO) & x (PTU) & x (PTU) & 100 \\
\hline$\beta$ Blocker (PO) & $\mathrm{x}$ & $\mathrm{x}$ & 100 \\
\hline \multicolumn{4}{|l|}{ Diabetes } \\
\hline Glucagon (SQ, IM) & $x$ & $x$ & 48 \\
\hline Metformin (PO) & $x$ & $x$ & 100 \\
\hline Sulfonylurea (PO) & & $x$ & 40 \\
\hline \multicolumn{4}{|l|}{ Water metabolism } \\
\hline Vasopressin analogues (SC, IV) & & & 28 \\
\hline Desmopressin acetate (NS, IN, SL, PO, IV) & $x(N S, I V)$ & $x(N S, I V)$ & 72 \\
\hline \multicolumn{4}{|l|}{ Gonads } \\
\hline GnRH agonists (IM) & & & 52 \\
\hline Testosterone (PO, transdermal, topical gel, IM) & & $x$ & 64 \\
\hline Calcitriol/1 $\alpha$ vitamin D3 (PO) & & & 52 \\
\hline Vitamin D2/D3 (PO) & $x$ & $x$ & 60 \\
\hline Bisphosphonates (PO or IV)† & & & 68 \\
\hline \multicolumn{4}{|l|}{ Hypoglycaemia } \\
\hline Diazoxide (PO) & & & 16 \\
\hline Somatostatin (SQ) & & & 52 \\
\hline \multicolumn{4}{|l|}{ Growth } \\
\hline Growth hormone (SQ) & & & 20 \\
\hline
\end{tabular}

${ }^{*}$ Per cent of countries including this category of medicines.

†Bisphosphonates include: alendronate and risedronate (PO) and ibandronate, pamidronate and zoledronate (IV).

EML, Model List of Essential Medicines; GnRH, gonadotropin-releasing hormone; H, human insulin; HCT, hydrocortisone; IM, intramuscular; IN, intranasal solution; IV, intravenous; NS, nasal spray; PDN, prednisone; PNL, prednisolone; PO, per orally; PTU, propylthiouracil; SL, sublingual; $\mathrm{SQ}$, subcutaneous.

\section{WHICH MEDICINES USED IN PAEDIATRIC} ENDOCRINOLOGY AND DIABETES ARE INCLUDED IN THE WHO MODEL LISTS OF ESSENTIAL MEDICINES?

The WHO maintains two Model Lists of Essential Medicines (EMLs), one for children and one for adults. ${ }^{11} 12$ These lists were last updated in April 2015 by an Expert Committee on the Selection and Use of Essential Medicines. ${ }^{10}$ They are used as a model, nonbinding guide for individual countries for the development of their own national EML. Since the publication of the first adult WHO EML for adults (1977) and for children (2007), the committee is constantly adapting 
to a changing scenery. Relevant to our analysis, the WHO has added expensive medicines to the EMLs when appropriate and has considered child-appropriate formulations. ${ }^{13}$

Table 1 compares the medicines included in our master list (left column) and the WHO EMLs for children and for adults (middle columns). Overall, the WHO EMLs include medicines that would enable appropriate management of vitamin $\mathrm{D}$ deficiency, type 1 and type 2 diabetes and most diseases of the adrenals, the thyroid gland and water metabolism. Medicines that are required for diseases of puberty and for contraception were included only in the WHO EML for adults as the age limit currently used as a cut-off for children is 12 years of age. We also identified several commonly used medicines that were not included in either of the two WHO lists: $1 \alpha$ vitamin $\mathrm{D} /$ calcitriol (eg, for hypocalcaemia secondary to hypoparathyroidism), diazoxide/somatostatin (eg, for hypoglycaemia secondary to hyperinsulinism), growth hormone (for neonatal hypoglycaemia secondary to growth hormone deficiency (GHD)) and bisphosphonates (eg, for osteogenesis imperfecta).

\section{SIMILARITIES AND DIFFERENCES BETWEEN THE WHO AND NATIONAL LISTS OF ESSENTIAL MEDICINES}

According to the WHO, the "National lists of essential medicines guide the procurement and supply of medicines in the public sector, schemes that reimburse medicine costs, medicine donations, and local medicine production". ${ }^{14}$ In most countries, national EMLs are prepared by a committee appointed by the Ministry of Health (MOH) and submitted to the WHO. They can be found on the WHO website in two complementary locations. ${ }^{14} 15$ Typically, the committee includes representatives from the MOH and from regional and local government health facilities in a multidisciplinary fashion (eg, physicians, nurses, pharmacologists, pharmacists, community health workers). ${ }^{16}$

We looked for all available national EMLs in Mexico, Central America, the Caribbean and South America and collected the following information for each country: date of the last revision of the EML, gross national income (GNI), and medicine names, form and dosage. Data were entered using the RedCap database (REDCap SoftwareVersion 6.5.20——C 2016 Vanderbilt University). Information could not be obtained from some countries or territories. First, several independent countries did not seem to have published a national EML, including Antigua and Barbuda, Bahamas, Grenada, Saint Kitts and Nevis, and Saint Lucia in the Caribbean and Guatemala and Panama in Central America. Second, many territories that have privileged relationships with France (Guadeloupe, Martinique, French Guyana), Netherlands (Aruba, Curacao, Sin Maarten and the Netherlands Antilles), UK (Anguilla, the British Virgin Islands, the Cayman Islands, Montserrat, and Turks and Caicos), and the USA (Navassa, Puerto Rico and the US Virgin Islands) may rely on the national EML list of countries with which they have these privileged contacts.

Table 2 shows the 25 countries for which we could collect national data (Mexico, 5 countries in Central America, 7 in the Caribbean, and 12 in South America) as well as the date of the most recent revision for the national EMLs. Most national EMLs were current within 10 years (mean year 2010, range 2004-2014). However, some lists may no longer accurately reflect the situation in an individual country. For example Venezuela's list was last reviewed and updated in 2004, and since that time the country has been under sociopolitical unrest. As a consequence, the government has failed to uphold support for Venezuela's health delivery programmes. ${ }^{17}$ In Brazil, 'long-standing problems in the country's healthcare system have been exacerbated by the economic and political crises'. ${ }^{18}$ Individual data for each of the countries are available in online supplementary table S1.

For thyroid diseases, all countries listed L-thyroxine and antithyroid drugs. However, while propylthiouracil

Table 2 Countries in South and Central America, the Caribbean and Mexico for which a national EML is available, presented by the year that each list was most recently updated

\begin{tabular}{ll}
\hline $\begin{array}{l}\text { Year of last updated } \\
\text { EML }\end{array}$ & Countries with a national EML \\
\hline 2004 & Venezuela \\
\hline 2005 & Argentina \\
\hline 2005 & Dominican Republic \\
\hline 2006 & Colombia \\
\hline 2008 & Jamaica \\
\hline 2009 & El Salvador \\
\hline 2009 & Nicaragua \\
\hline 2009 & Paraguay \\
\hline 2010 & Brazil \\
\hline 2010 & Chile \\
\hline 2010 & Costa Rica \\
\hline 2010 & Guyana \\
\hline 2010 & Peru \\
2010 & Saint Vincent and the \\
\hline 2010 & Grenadines \\
\hline 2011 & Trinidad and Tobago \\
\hline 2011 & Belize \\
\hline 2011 & Honduras \\
\hline 2011 & Mexico \\
\hline 2012 & Uruguay \\
\hline 2012 & Barbados \\
\hline 2012 & Cuba \\
\hline 2013 & Haiti \\
\hline 2013 & Bolivia \\
\hline 2014 & Ecuador \\
\hline$E M L$, & Suriname \\
\hline
\end{tabular}

EML, Model List of Essential Medicines. 
(PTU) is the only antithyroid medicine suggested by the $\mathrm{WHO}$, many countries list methimazole $(44 \%)$ and carbimazole (28\%) in their national EMLs. In 2010, following the identification of rare but significant side effects of PTU (fatal liver failure), the Food and Drug Administration ${ }^{19}$ added a Boxed Warning to the label for PTU, which is not acceptable anymore as a first-line treatment for hyperthyroidism. ${ }^{20}$ We suggest that the inclusion of this medicine in the WHO EMLs should be reconsidered on the grounds that safer alternatives are available.

For adrenal diseases, all countries had at least one of the oral corticosteroids commonly used in paediatrics to replace cortisol (hydrocortisone, prednisone or prednisolone). However, fludrocortisone, an affordable medicine that is lifesaving for patients with a salt wasting form of congenital adrenal hyperplasia, remains difficult to access. Fludrocortisone was added to the WHO EMLs following a submission by CLAN in 2008 but is only included by $48 \%$ of the countries. ${ }^{21}$ Reasons for poor availability in countries such as Peru, Bolivia and Ecuador include lack of awareness of health authorities, cost of the medicine and cost to the pharmaceutical industry for registering a low-cost medicine that serves a small market.

For diabetes, all countries included at least one shortacting insulin and $96 \%$ included at least one long-acting insulin. Short-acting analogues were included in 11 (44\%) national EMLs and long-acting analogues in 7 (28\%) national EMLs. In contrast, glucagon, which is included in both the WHO lists, was only included in 12 countries $(48 \%)$.

For diseases of calcium/bone, vitamin D3 (for the prevention and treatment of rickets due to vitamin $\mathrm{D}$ deficiency) is included in both the WHO EMLs but only in the national EMLs of 15 countries $(60 \%)$.

To manage puberty, paediatric endocrinologists commonly use testosterone in boys, and oral contraceptives and oestradiol in girls. These medicines were available in most, but not all, of the national EMLs, but only testosterone and oral contraceptives were listed in the WHO EML for adults.

For the management of congenital hyperinsulinism, diazoxide and somatostatin were only available in a few countries $(16 \%)$.

Bisphosphonates, essential for the treatment of osteogenesis imperfecta among other bone diseases, are not included in either of the WHO EMLs, but are included in 17 countries $(68 \%)$. We agree on the importance of this medicine and suggest that the addition of bisphosphonates to the WHO EMLs should be considered, especially since many of the class are now off patent and prices have fallen substantially.

Growth hormone is included by $20 \%$ of the individual countries but is absent from the WHO EML for children or adults. In infants with true GHD, human growth hormone $(\mathrm{hGH})$ is essential for the prevention and management of hypoglycaemia. In older GHD children, it improves final height and body composition. However, in HICs, the availability of hGH has led to the treatment of many thousands of short but healthy, non-GHD children with unclear benefits and potential long-term risks. ${ }^{22} \mathrm{~A}$ similar comment could be made about recombinant insulin-like growth factor 1 (rIGF-1) that is used so rarely in paediatric endocrinology that it was not included in our master list. In Ecuador, a small number of children present with growth hormone receptor deficiency (GHRD), a genetically inherited condition that results in a very short adult height and causes increased mortality at early ages. ${ }^{23}$ GHRD can be managed with rIGF- $1 .^{24}$ Since the vast majority of these patients are clustered in a small area of Ecuador (among the countries we surveyed), this medicine is specifically relevant for this population. hGH and rIGF-1 are expensive medicines and their inclusion in the EMLs could promote unwanted use resulting in inappropriate healthcare expenses. These two examples illustrate the challenges of designing a national EML for less common diseases requiring more expensive medicines. Clarifying the country's prevalence of a condition (often unknown in LMICs), achieving a formal diagnosis (that may challenge the country's capacity) and proposing an age at which the patient would most benefit from the medicine are issues that need to be considered when designing a national EML, acknowledging that such specific recommendations may be difficult to implement.

Comparison between the WHO and the national EMLs has been used as an indicator of whether countries are promoting access to paediatric medicines. ${ }^{25}{ }^{26}$ Overall, there were discrepancies between the medicines included in the $\mathrm{WHO}$ and in the national EMLs (table 1, right column). National EMLs generally included fewer medicines than the WHO EMLs. Indeed, while essential medicines are selected by the WHO based on evidence of efficacy, safety, dose and cost-effectiveness, individual countries take into account additional factors such as local prevalence of disease, availability of treatment facilities, cost and health professional experience. Interestingly, more expensive medicines used for the management of less common diseases such as somatostatin, diazoxide and bisphosphonates and that are not included in the WHO EMLs were found in several EMLs from mostly richer countries (figure 1). This may reflect a proactive attitude of the $\mathrm{MOH}$ in these countries. Considering the worldwide recognition of the WHO lists as a benchmark, it may be important that in future meetings, the Expert Committee on the Selection and Use of Essential Medicines consider whether medicines included unilaterally by specific countries should also be included in the WHO EMLs. This may ultimately promote the adoption of a larger number of medicines by more individual countries.

\section{GNI INFLUENCES THE CONTENT OF THE NATIONAL LISTS OF ESSENTIAL MEDICINES}

GNI data were obtained from the World Bank, which calculates GNIs based on the World Bank Atlas 


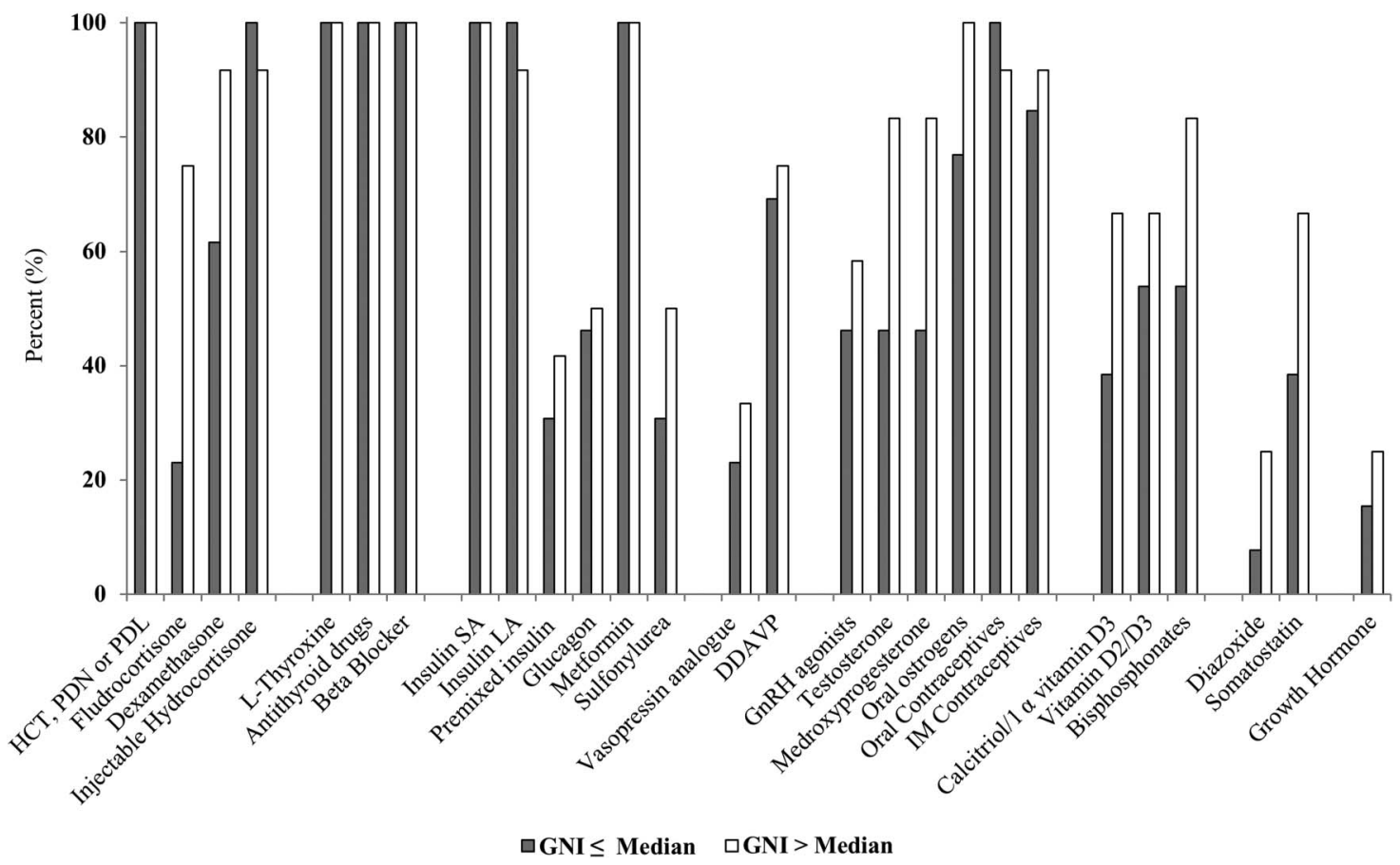

Figure 1 Per cent of countries including each medicine or category of medicines, as a function of the median GNI. The grey bars represent the 13 countries below the median $\mathrm{GNI}$ and the white bars represent the 12 countries above the median GNI. DDAVP, desmopressin acetate; GNI, gross national income; $\mathrm{GnRH}$, gonadotropin-releasing hormone; HCT, hydrocortisone; IM, intramuscular; LA, long-acting; PDL, prednisolone; PDN, prednisone; SA, short-acting.

Method. $^{27}$ Figure 1 compares the availability of each medicine or category of medicines as a function of the national GNI. Overall, richer countries included more medicines than poorer countries (Spearman Rank Correlation Coefficient (r) 0.57 (95\% CI 0.23 to 0.79), $\mathrm{p}<0.01$ ) (figure 2). The per cent of countries including a specific medicine or category of medicines ranged from $16 \%$ to $100 \%$. Medicines that address the most common needs (corticoid treatment, hypothyroidism and hyperthyroidism, type 1 and type 2 diabetes, and contraception) were included in most national EMLs irrespective of GNI. In contrast, fludrocortisone was available in nine $(75 \%)$ of the richest countries and only in three $(23 \%)$ of the poorest countries (figure 1). Among insulins, shortacting analogues were included in only five $(39 \%)$ of the poorest countries, and long-acting analogues in only two $(15 \%)$ of the poorest countries. Bisphosphonates were listed in $10(83 \%)$ of the top $50 \%$ richer countries and $7(54 \%)$ of the poorest $50 \%$. However, intravenous bisphosphonates (newer and more potent than the oral form) were included in only eight $(67 \%)$ of the richest countries, and in four $(31 \%)$ of the poorest countries. Growth hormone is only included in the national EML of four countries which are all part of the upper middle income group.

\section{POLICY IMPLICATIONS AND RECOMIMENDATIONS}

The present analysis focuses on access to medicines in paediatric endocrinology and diabetes, an area that has

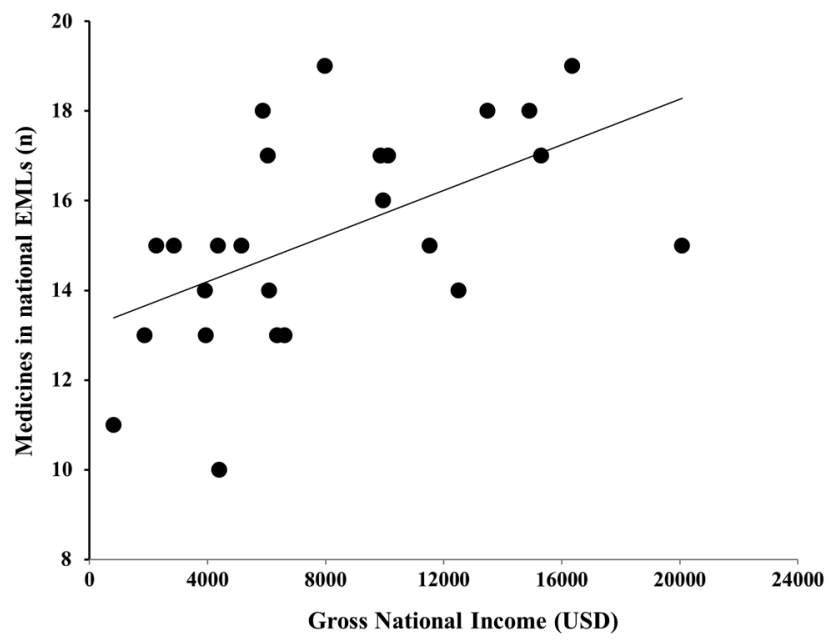

Figure 2 Relationship between gross national income and number of medicines that are included both in the WHO and national Model Lists of Essential Medicines (EMLs) for each of the 25 countries included in the analysis. Spearman Rank Correlation Coefficient (r) $0.57(95 \% \mathrm{Cl} 0.23$ to 0.79$), p<0.01$.

received little interest in resources-limited settings until now. The increase in capacity in this paediatric specialty, the increasing relative importance of NCDs in overall child mortality, and the goal to achieve equitable access to healthcare are all driving the interest to improve care for the many thousands of children with paediatric endocrine conditions and diabetes living in LMICs. We expect that this trend will also develop for other paediatric specialties. 
Paediatric endocrinology focuses on growth, which is related more to pubertal development than to age. The WHO presently sets 12 years of age as the limit between a child and an adult, with the rationale that older children can be given dosage forms of medications that are designed for adults. ${ }^{28}$ Accordingly, testosterone and contraceptives were included in the adult but not the paediatric WHO EML. We suggest that a definition based on physical maturity (end of pubertal development or final height) would be better suited. Indeed, pubertal development and growth are critical periods that present specific challenges best addressed by paediatricians. Although in many countries children are presently followed by adult physicians, capacity in paediatric specialties is increasing and revising the age cut-off would ensure that the EML for children truly meets their best interests.

Most national EMLs were written in the official language of the country (Spanish, Portuguese, English, French or Dutch). Although they used the category numbers and format proposed by the WHO, at least one list did not include the route of administration or the dose of the medicines. Formatting the lists in a similar manner or making an English translation available could promote collaborative projects around regional registration of medicines or use of medicines with the same characteristics.

Diabetes and several paediatric endocrine conditions require lifelong management and multifaceted approaches. For instance, diabetes requires insulin as well as glucagon (and other non-drug supplies such as metres and strips for blood glucose measurement). We propose that essential medicines be systematically presented in a disease-focused manner and be promoted together. ${ }^{29}{ }^{30}$ This is the case for childhood cancer, where the WHO recently promoted a more effective disease-based approach compared with an agent-based approach. ${ }^{31} 32$ Addressing essential medicines in a holistic fashion may improve disease management.

\section{CONCLUSIONS}

The WHO and national EMLs are key steps towards achieving better access to medicines and there is no underestimating the challenge of overcoming the many barriers preventing the achievement of this objective. Access to medicines for paediatric endocrine conditions and diabetes illustrates the complex issues and the increasing cost surrounding management of less common conditions. This problem is, however, not limited to LMICs ${ }^{33-36}$ and challenges the objective of universal healthcare, which is 'to ensure that all people obtain the health services they need without suffering financial hardship when paying for them' ${ }^{37}$

It should be remembered that while optimal access to safe and affordable medicines is important, it is only one aspect of the successful management of paediatric endocrine conditions and diabetes. Better knowledge of the prevalence of paediatric endocrine conditions in LMICs, capacity building and diagnostic tools that are adapted to the needs of a country, clinical research serving the needs of a population, constructive relationships between the pharmaceutical industry, health authorities, health professionals and families, as well as education and leadership of patient groups, are other key components of better care. ${ }^{6} 38$

In future projects, GPED ${ }^{2}$ will investigate whether the national EMLs generated by the WHO member countries actually reflect the availability of the medicine in the country of interest, in particular where public and private health systems coexist. Anecdotal evidence reported in this paper and in published literature suggests that it is not necessarily the case. ${ }^{16}$

\section{Author affiliations}

${ }^{1}$ Endocrinology and Diabetes Unit, British Columbia Children's Hospital and University of British Columbia, Vancouver, British Columbia, Canada

${ }^{2}$ Global Pediatric Endocrinology and Diabetes (GPED), Vancouver, British Columbia, Canada

${ }^{3}$ Colegio de Medicina, Universidad San Francisco de Quito, Quito, Ecuador

Handling editor Soumitra Bhuyan

Acknowledgements The authors wish to thank Dr Suzanne Hill, WHO Geneva, for the insightful contributions to the discussion of this article.

Contributors AR did the literature search, collected and interpreted the data and wrote the draft of the manuscript and of the figures. AA and JG-A critically reviewed the master list of medicines, read the manuscript and provided input on the interpretation of the data and on the discussion. J-PC designed the study, led the focus group for the master list of medicines, discussed the interpretation of the results, and revised the manuscript and the figures. All authors have read and approved the manuscript. J-PC had full access to all the data in the study and had final responsibility for the decision to submit for publication.

Competing interests None declared.

Provenance and peer review Not commissioned; externally peer reviewed.

Data sharing statement All data are available to all authors.

Open Access This is an Open Access article distributed in accordance with the Creative Commons Attribution Non Commercial (CC BY-NC 4.0) license, which permits others to distribute, remix, adapt, build upon this work noncommercially, and license their derivative works on different terms, provided the original work is properly cited and the use is non-commercial. See: http:// creativecommons.org/licenses/by-nc/4.0/

\section{REFERENCES}

1. Boerma T, Mathers C, AbouZahr C, et al. Chapter 6: Noncommunicable diseases. In: Health in 2015: from MDGs, Millennium Development Goals to SDGs, Sustainable Development Goals. The World Health Organization. 2015:131-52. http://www. who.int/gho/publications/mdgs-sdgs/MDGs-SDGs2015_chapter6. pdf?ua=1 (accessed 19 Oct 2016).

2. Global Pedatric Endocrinology and Diabetes. GPED (cited 29 March 2016). http://www.globalpedendo.org/index.htm

3. Sociedad Latino Americana De Endocrinologia Pediatrica. Sociedad Latino Americana De Endocrinologia Pediatrica. 2010 (cited 22 March 2016). http://www.slep.com.br/slep.php?f=contenido\&id= homepage_en\&g=homepage\&lang=en

4. Pediatric Endocrine Society. International Scholars Program PES. 2016 (cited 29 March 2016). https://www.pedsendo.org/research_ awards/international_scholars/index.cfm

5. Emmerick IC, Luiza VL, Camacho LA, et al. Barriers in household access to medicines for chronic conditions in three Latin American countries. Int J Equity Health 2015;14:115.

6. CLAN. Caring and Living as Neighbours: CLAN. 2012 (cited 24 March 2016). http://www.clanchildhealth.org/ 
7. International Diabetes Federation. Life for a child. 2015 (cited 15 August 2016). http://www.idf.org/lifeforachild

8. CARES Foundation. 2014 (cited 15 August 2016). http://www. caresfoundation.org/

9. World Health Organization. The selection and use of essential medicines: Report of the WHO Expert Committee, 2011 (including the 17th WHO model list of essential medicines and the 3rd WHO model list of essential medicines for children). Selection and Use of Essential Medicines: Report of the Who Expert Committee, 2011. 2011:965:1-249.

10. Reidenberg MM. World Health Organization program for the selection and use of essential medicines. Clin Pharmacol Ther 2007;81:603-6.

11. World Health Organization. WHO model list of essential medicines for children. 5th edn. 2015 (cited 15 March 2016). http://www.who.int/ medicines/publications/essentialmedicines/EMLc_2015_FINAL_ amended AUG2015.pdf?ua $=1$

12. World Health Organization. WHO model list of essential medicines. 19th edn. 2015 (cited 15 March 2016). http://www.who.int/selection medicines/committees/expert/20/EML_2015_FINAL_amended_ AUG2015.pdf?ua $=1$

13. Gray AL, Wirtz VJ, t Hoen EF, et al. Essential medicines are still essential. Lancet 2015;386:1601-3.

14. World Health Organization. Essential medicines selection: Department of Essential Medicines and Health Products. 2016 (cited 15 March 2016). http://www.who.int/selection_medicines/country_ lists/en/

15. World Health Organization. Essential medicines and health products information portal. 2016 (cited 15 March 2016). http://apps.who.int/ medicinedocs/en/q/

16. PATH, The World Health Organization, Fund TUNP. Essential medicines for reproductive health: guiding principles for their inclusion on national medicines lists. Seattle: PATH; 2006. http://www.who.int/medicines/publications/EssMeds_RHealth.pdf (accessed 19 Oct 2016)

17. Oletta JF, Orihuela RA, Pulido P, et al. Venezuela: violence, human rights, and health-care realities. Lancet 2014;383:1967.

18. Watts J. Brazil's health system woes worsen in economic crisis. Lancet 2016;387:1603-4.

19. U.S. Food and Drug Administration. FDA Drug Safety Communication. New boxed warning on severe liver injury with propylthiouracil. U.S. Department of Health and Human Services, 2010 (cited 25 March 2016). http://www.fda.gov/Drugs/DrugSafety/PostmarketDrugSafety InformationforPatientsandProviders/ucm209023.htm

20. Rivkees SA, Mattison DR. Propylthiouracil (PTU) hepatoxicity in children and recommendations for discontinuation of use. Int $J$ Pediatr Endocrinol 2009;2009:132041.

21. Warne G, Sung V, Raza SJ, et al. Application for inclusion of fludrocortisone tablets in the WHO Model List of Essential Medicines for children. Second Meeting of the Subcommittee of the Expert Committee on the Selection and Use of Essential Medicines. 2008. http://www.who.int/selection_medicines/committees/subcommittee/2/ FLUDRO.pdf (accessed 19 Oct 2016).

22. Allen DB. Clinical review: lessons learned from the hGH era. J Clin Endocrinol Metab 2011:96:3042-7.

23. Rosenfeld RG, Rosenbloom AL, Guevara-Aguirre J. Growth hormone $(\mathrm{GH})$ insensitivity due to primary $\mathrm{GH}$ receptor deficiency. Endocr Rev 1994;15:369-90.

24. Guevara-Aguirre J, Rosenbloom AL, Guevara-Aguirre M, et al. Recommended IGF-I dosage causes greater fat accumulation and osseous maturation than lower dosage and may compromise long-term growth effects. J Clin Endocrinol Metab 2013;98:839-45.

25. Hill S, Yang A, Bero L. Priority medicines for maternal and child health: a global survey of national essential medicines lists. PLOS ONE 2012;7:e38055.

26. Barr R, Robertson J. Access to cytotoxic medicines by children with cancer: a focus on low and middle income countries. Pediatr Blood Cancer 2016;63:287-91.

27. The World Bank. GNI per capita, Atlas method (current US\$). 2016 (cited 15 March 2016). http://data.worldbank.org/indicator/NY.GNP. PCAP.CD

28. World Health Organization. The selection and use of essential medicines: report of the WHO Expert Committee, October 2007 (including the model list of essential medicines for children). Who Tech Rep Ser 2008;950:1-174

29. Beran D. Developing a hierarchy of needs for type 1 diabetes. Diabet Med 2014;31:61-7.

30. Beran D, Yudkin JS. Looking beyond the issue of access to insulin what is needed for proper diabetes care in resource poor settings. Diabetes Res Clin Pract 2010;88:217-21.

31. Robertson J, Magrini N, Barr R, et al. Medicines for cancers in children: the WHO model for selection of essential medicines. Pediatr Blood Cancer 2015;62:1689-93.

32. Ward E, DeSantis C, Robbins A, et al. Childhood and adolescent cancer statistics, 2014. CA Cancer J Clin 2014;64:83-103.

33. Magrini N, Robertson J, Forte G, et al. Tough decisions on essential medicines in 2015. Bull World Health Organ 2015;93:283-4.

34. Hogerzeil HV. The concept of essential medicines: lessons for rich countries. BMJ 2004;329:1169-72.

35. Forman J, Taruscio D, Llera VA, et al. The need for worldwide policy and action plans for rare diseases. Acta Paediatr 2012;101:805-7.

36. Cohen J, Milne CP. Is the increasing cost of treating rare diseases sustainable? Expert Opin Orphan Drugs 2013:1:581-3.

37. World Health Organization. What is Universal Health Coverage? 2016 (cited 22 August 2016). http://www.who.int/universal_health_ coverage/en/

38. Zacharin M, Chanoine JP, Cassorla F, et al. Promoting excellence in the care of pediatric endocrine diseases in the developing world. Pediatrics 2013;131:e573-8. 